\title{
Expression of CD55, CD59, and CD35 on red blood cells of $\beta$-thalassaemia patients
}

\author{
AYŞEGÜL UĞUR KURTOĞLLU', BELKLS KOÇTEKIN², ERDAL KURTOĞLU", \\ MUSTAFA YILDIZ4 ${ }^{4}$ SELEN BOZKURT ${ }^{5}$ \\ ${ }^{1}$ Department of Biochemistry, Antalya Education and Research Hospital, Antalya, Turkey \\ ${ }^{2}$ Department of Tranfusion Center, Antalya Education and Research Hospital, Antalya, Turkey \\ ${ }^{3}$ Department of Hematology, Antalya Education and Research Hospital, Antalya, Turkey \\ ${ }^{4}$ Department of Medical Oncology, Antalya Education and Research Hospital, Antalya, Turkey \\ ${ }^{5}$ Department of Biostatistics Medical Informatics, Faculty of Medicine, Akdeniz University, Antalya, Turkey
}

\begin{abstract}
Aim of the study: $\beta$-thalassaemia ( $\beta$-Thal) is considered a severe, progressive haemolytic anaemia, which needs regular blood transfusions for life expectancy. Complement-mediated erythrocyte destruction can cause both intravascular and extravascular haemolysis. Complement regulatory proteins protect cells from such effects of the complement system. We aimed to perform quantitative analysis of membrane-bound complement regulators, CD55 (decay accelerating factor-DAF), CD35 (complement receptor type $1-C R 1)$, and CD59 (membrane attack complex inhibitory factor-MACIF) on peripheral red blood cells by flow cytometry.

Material and methods: The present study was carried out on $47 \beta$-thalassemia major $(\beta-T M)$ patients, $20 \beta$-thalassaemia intermedia ( $\beta$-TI) patients, and 17 healthy volunteers as control subjects.

Results: CD55 levels of $\beta$-TM patients $(58.64 \pm 17.06 \%)$ were significantly decreased compared to $\beta$-TI patients $(83.34 \pm 13.82 \%)$ and healthy controls $(88.57 \pm 11.69 \%)(p<0.01)$. CD59 levels of $\beta-T M$ patients were not significantly different than $\beta$-TI patients and controls, but CD35 levels were significantly lower in the $\beta$-TM patients $(3.56 \pm 4.87 \%)$ and $\beta$-TI patients $(12.48 \pm 9.19 \%)$ than in the control group $(39.98 \pm 15.01 \%)(p<0.01)$.

Conclusions: Low levels of CD55 and CD35 in thalassaemia major patients indicates a role for them in the aetiopathogenesis of haemolysis in this disease, and also this defect in a complement system may be responsible for the chronic complications seen in these patients.
\end{abstract}

Key words: CD55, CD59, CD35, $\beta$-thalassemia.

(Cent Eur J Immunol 2017; 42 (1): 78-84)

\section{Introduction}

$\beta$-thalassaemia ( $\beta$-Thal) is an inherited chronic haemolytic anaemia resulting from absent or low level of synthesis of $\beta$-globin chains of haemoglobin A in erythropoietic cells [1]. The clinical manifestations of $\beta$-thalassaemia are extremely varied, spanning a broad spectrum from the transfusion-dependent state of $\beta$-thalassaemia major ( $\beta$-TM) to the asymptomatic state of thalassaemia trait. The clinical syndrome of $\beta$-thalassaemia intermedia ( $\beta$-TI) lies between these two clinical extremes. It comprises a wide spectrum of phenotypes from a condition that is slightly less severe than $\beta$-TM to one that is asymptomatic and often identified through a routine blood test [2]. The excess $\alpha$-globin tetramer formation and interaction with the red cell membrane lead to haemolytic anaemia and hyperplasia of erythroid precursors [3]. Other mechanisms have been reported to be responsible for red cell lysis besides this mechanism, and to aggravate the haemolysis in $\beta$-Thal patients [4].

The complement system is an important part of innate immune response that may be implicated in red blood cell (RBC) lysis. Mammalian cells are provided with surface-bound complement regulatory proteins (MCRPs) that regulate the activation of complement cascade, thus protecting them from uncontrolled complement-mediated lysis [5]. Decay accelerating factor (DAF, CD55) is a membrane-bound regulatory protein that downregulates the complement cascade at the critical step of $\mathrm{C} 3$ activation. Failure to regulate C3 and C5 convertase enzymes allows cytolytic membrane attack complex (MAC) to be generated on the surface of cells [6]. CD59, a membrane-bound complement regulatory protein, prevents MAC formation by inhibiting the incorporation of $\mathrm{C} 9$ [7]. Another membrane-bound protein CD35 (Complement receptor 1) is

Correspondence: Ayşegül Uğur Kurtoğllu, Department of Biochemistry, Antalya Education and Research Hospital, Antalya, 07050 Turkey, e-mail: ugurkurtoglu@yahoo.com

Submitted: 20.06.2016; Accepted: 17.10.2016 
very important for processing and clearing complement opsonised immune complexes and acts as a negative regulator of the complement cascade, mediates immune adherence and phagocytosis, and inhibits both classical and alternative pathways. It plays an important role in the removal of immune complexes and pathogens coated with $\mathrm{C} 3 \mathrm{~b}$ and $\mathrm{C} 4 \mathrm{~b}$.

$\mathrm{CD} 35$ presents $\mathrm{C} 3 \mathrm{~b}$ or $\mathrm{C} 4 \mathrm{~b}$ to protease to cleave them and stop the cascade of activation [8]. Decreases in complement regulatory protein $(\mathrm{CrP})$ levels may predispose $\mathrm{RBCs}$ to destruction by complement activation, thus contributing to the development of anaemia [9]. Complement regulatory proteins are absolutely required to protect RBC from spontaneous complement damage, and $\mathrm{CrP}$ deficiencies render RBC more susceptible to complement damage [10].

In the present study, aimed at understanding the pathogenesis of anaemia in $\beta$-Thal, we analysed the level of expression of CD55, CD59, and CD35 on peripheral RBCs by flow cytometry.

\section{Material and methods}

\section{Subjects}

This study was conducted on a total of 70 patients at the Thalassaemia Centre of Antalya Education and Research Hospital, Antalya, Turkey. Transfusion-dependent and multi-transfused $\beta$-TM and $\beta$-TI patients aged 18-45 years were included in the study. Three with $\mathrm{Hb} \mathrm{S} / \beta$-thalassaemia were excluded from the final analysis. The control group consisted of 17 healthy subjects aged 18-45 years. Patients were previously diagnosed as $\beta$-Thal by clinical and laboratory examinations including high performance liquid chromatography (HPLC). They were classified as $47 \beta$-TM and $20 \beta$-TI phenotypes. The following criteria were used for the diagnosis of $\beta$-TI: a transfusion history of more than two years at the time of diagnosis, less than eight units of transfusion per year, and a pre-transfusion haemoglobin level of more than $7 \mathrm{~g} / \mathrm{dl}$. These patients were seen during their routine follow-up visits at the outpatient clinic, and a detailed history was taken from all patients regarding age, time of the first blood transfusion, time of the last transfusion, frequency of transfusions, and other information concerning the patient's status. $\beta$-TM patients received blood transfusion according to their blood counts (15-30-day intervals) whereas $\beta$-TI patients received blood transfusion as needed, not at regular intervals. Eight patients were diagnosed with diabetes mellitus, 11 patients had cardiac valvular problems, and 47 patients had osteoporosis. Peripheral blood samples were collected in K2-EDTA vacutainer tubes just before receiving the transfusion. The analyses were carried out promptly, including a complete blood count (CBC) that was performed for all patients and control subjects using a haematology analyser (Coulter LH 780 Analyzer, Beckman Coulter). This study was performed with the approval of the Ethics Committee of the Education and Research Hospital, Antalya, Turkey. All subjects were informed about the objectives and procedures of the study, and informed consent was obtained from each subject.

\section{Flow cytometric analysis of CD55, CD59, and $\mathrm{CD} 35$ on the cell membrane of red blood cells $(\mathbf{R B C})$}

The EDTA blood sample was processed within one hour. The blood sample was diluted with phosphate-buffered saline (PBS) to achieve 10,000 RBC/ $\mu$ l concentration. Then $100 \mu \mathrm{l}$ of diluted blood was transferred to a polystyrene tube, and to each polystyrene tube $10 \mu \mathrm{l}$ of monoclonal antibodies against CD55 (PE Mouse Anti-Human), CD59 (FITC Mouse Anti-Human), and CD35 (PE Mouse Anti-Human) were added. After 30 minutes of incubation in the dark at room temperature, samples were washed two times with PBS. Finally, the pellet was resuspended in $0.5 \mathrm{ml}$ PBS and cells were analysed in a flow cytometer (FACS Canto II, Becton-Dickinson).

\section{Statistical analysis}

For data description, maximum, minimum, mean, standard deviation (SD), and median were tabulated. The Shapiro-Wilk test was used to verify the normality of the distribution of continuous variables. Statistical analysis of clinical data between two groups (control vs. patients) consisted of unpaired t-tests for parametric data and Mann Whitney $\mathrm{U}$ test analysis for nonparametric data. Analyses were performed with PASW 20 (SPSS/IBM, Chicago, IL, USA) software, and a two-tailed $p$-value less than 0.05 was considered statistically significant.

\section{Results}

There was no statistically significant difference regarding age and gender between $\beta$-TM patients, $\beta$-TI patients, and the control group. The patients had been previously diagnosed by clinical and laboratory examinations including HPLC and complete blood count. The haematological parameters of the patients and controls are summarised in Table 1.

The levels of CD55, CD59, and CD35 expressions on peripheral blood erythrocytes by flow cytometric analysis were compared between three groups, $\beta$-TM patients, $\beta$-TI patients, and control groups, as shown in Table 2 . The overall (mean \pm SD) percentage of CD55-positive RBCs of $\beta$-TM patients was significantly lower (58.64 $\pm 17.06 \%)$ than for the $\beta$-TI patients $(83.34 \pm 13.83 \%)$ and healthy controls $(88.57 \pm 11.69 \%)(p<0.01)$. The overall mean percentages of CD55-positive RBCs of $\beta$-TI patients and healthy controls were not significantly different. The overall mean percentages of CD59-positive RBCs of $\beta$-TM patients $(97.08 \pm 7.81 \%)$ and $\beta$-TI patients $(93.52 \pm 4.38 \%)$ 
Table 1. Haematological parameters of $\beta$-TM, $\beta$-TI, and healthy controls

\begin{tabular}{lcccc}
\hline Parameters & $\begin{array}{c}\beta-\text { TM Patients } \\
\text { Mean } \pm \text { SD }\end{array}$ & $\begin{array}{c}\beta \text {-TI Patients } \\
\text { Mean } \pm \text { SD }\end{array}$ & $\begin{array}{c}\text { Controls } \\
\text { Mean } \pm \text { SD }\end{array}$ & $p$ values \\
\hline $\mathrm{RBC}$ count $(1012 / \mathrm{l})$ & $3.24 \pm 0.4$ & $3.66 \pm 0.37$ & $4.81 \pm 0.38$ & $<0.001^{\mathrm{a}, \mathrm{b}, \mathrm{c}}$ \\
\hline $\mathrm{Hb}(\mathrm{g} / \mathrm{dl})$ & $8.8 \pm 0.80$ & $8.46 \pm 0.73$ & $14.27 \pm 1.34$ & $<0.001^{\mathrm{a}, \mathrm{b}}$ \\
\hline $\mathrm{MCV}(\mathrm{fL})$ & $81.42 \pm 4.03$ & $74.76 \pm 7.95$ & $87.34 \pm 2.78$ & $<0.001^{\mathrm{a}, \mathrm{b}, \mathrm{c}}$ \\
\hline $\mathrm{MCH}(\mathrm{pg})$ & $27.38 \pm 1.75$ & $23.32 \pm 2.61$ & $29.69 \pm 1.36$ & $<0.001^{\mathrm{a}, \mathrm{b}, \mathrm{c}}$ \\
\hline $\mathrm{MCHC}(\mathrm{g} / \mathrm{dl})$ & $33.63 \pm 1.23$ & $31.23 \pm 1.75$ & $34.00 \pm 0.87$ & 0.263 \\
\hline $\mathrm{RDW}(\%)$ & $18.08 \pm 6.00$ & $27.40 \pm 4.83$ & $13.29 \pm 0.71$ & $<0.001^{\mathrm{a}, \mathrm{b}, \mathrm{c}}$ \\
\hline${ }^{a} p<0.05 \beta-T M$ patients compared to the healthy controls \\
${ }^{p} p<0.05 \beta-T I$ patients compared to the healthy controls \\
${ }^{p} p<0.05 \beta-T M$ patients compared to $\beta$-TI patients
\end{tabular}

Table 2. The levels of CD55, CD59, and CD35 expression for $\beta$-TM and $\beta$-TI patients compared to the normal healthy controls

\begin{tabular}{lcccc}
\hline & $\begin{array}{c}\beta \text {-TM Patients } \\
\text { Mean } \pm \text { SD }\end{array}$ & $\begin{array}{c}\beta \text {-TI Patients } \\
\text { Mean } \pm \text { SD }\end{array}$ & $\begin{array}{c}\text { Controls } \\
\text { Mean } \pm \text { SD }\end{array}$ & $p$ values \\
\hline CD 55 & $58.64 \pm 17.06$ & $83.34 \pm 13.82$ & $88.57 \pm 11.69$ & $<0,001 *$ \\
\hline CD 59 & $97.08 \pm 7.81$ & $93.52 \pm 4.38$ & $99.75 \pm 0.39$ & 0.167 \\
\hline CD 35 & $3.56 \pm 4.87$ & $12.48 \pm 9.19$ & $39.98 \pm 15.01$ & $<0,001 *$ \\
\hline
\end{tabular}

were not significantly different than controls $(99.75$ $\pm 0.39 \%)$. The overall mean percentage of CD35-positive RBCs of $\beta$-TM patients was significantly lower (3.56 $\pm 4.87 \%)$ than $\beta$-TI patients $(12.48 \pm 9.19 \%)$ and healthy controls $(39.98 \pm 15.01 \%)(p<0.01)$. The overall mean percentage of CD35-positive RBCs of $\beta$-TI patients was significantly lower than healthy controls $(p<0.01)$. Figure 1 represents scattering of RBCs stained with anti-CD55 PE, anti-CD59 FITC, and anti-CD35 PE in healthy controls. Figure 2 represents scattering of RBCs stained with anti-CD55 PE, anti-CD59 FITC, and anti-CD35 PE in $\beta$-TM patients. Figure 3 represents scattering of RBCs stained with anti-CD55 PE, anti-CD59 FITC, and anti-CD35 PE in $\beta$-TI patients.

\section{Discussion}

Chronic transfusions are the mainstay of treatment for patients with severe $\beta$-TM. Iron overload is a major source of morbidity and mortality in both transfusion-dependent and non-dependent thalassaemia patients necessitating iron chelation therapy. Iron overload contributes to increased risk of cirrhosis, heart failure, and endocrinopathies, while ineffective erythropoiesis and haemolysis contribute to multiple complications including splenomegaly, extramedullary haematopoiesis, pulmonary hypertension, and thrombosis [11]. Haemolysis is a common feature in patients with $\beta$-TM. Ineffective erythropoiesis and haemolysis leads to the conspicuous anaemia seen in the $\beta$-TM, which can be corrected with repeated blood transfusions [12].
Normal cell membranes express CrPs that regulate activation of the complement system and provide essential protection against self-damage [13]. Many studies show that CrPs may play an important role in protecting RBC from destruction through the activation of complement [9]. A number of haemolytic disorders are caused by mutations and/or autoantibodies that inactivate $\mathrm{CrPs}$ and mutations that directly activate the complement cascade [10]. CD55, CD59, and CD35 proteins on the cell surfaces block complement activation. Loss of these proteins makes the blood cell susceptible to haemolysis [14]. There are studies of CD55, CD59, and CD35 levels in diseases having a haemolytic course, such as malaria, paroxysmal nocturnal haemoglobinuria, and autoimmune haemocytopaenia [15-17].

Haemolysis and related complications play a very important role in $\beta$-TM patients, but studies about cascade system aiming to understand the aetiopathogenesis of the haemolysis are fewer in number. Most of the present studies are related to CD55 and CD59 levels [18], but there are no data about CD35 levels in $\beta$-TM patients.

In this study we measured CD35 levels as well as CD55 and CD59 levels. CD55 levels of $\beta$-TM patients were significantly decreased compared to $\beta$-TI patients and healthy controls. CD59 levels of all of the patients were not significantly different than for the control group, but CD35 levels were significantly lower in the $\beta$-TM patients and $\beta$-TI patients compared to the control group.

Obaid et al. found that expression of CD55 on the RBCs of $\beta$-thalassaemia patients was diminished below that of healthy controls, while CD59 was not affected, in a study held in $32 \beta$-thalassaemia patients ( $21 \beta$-TM and 

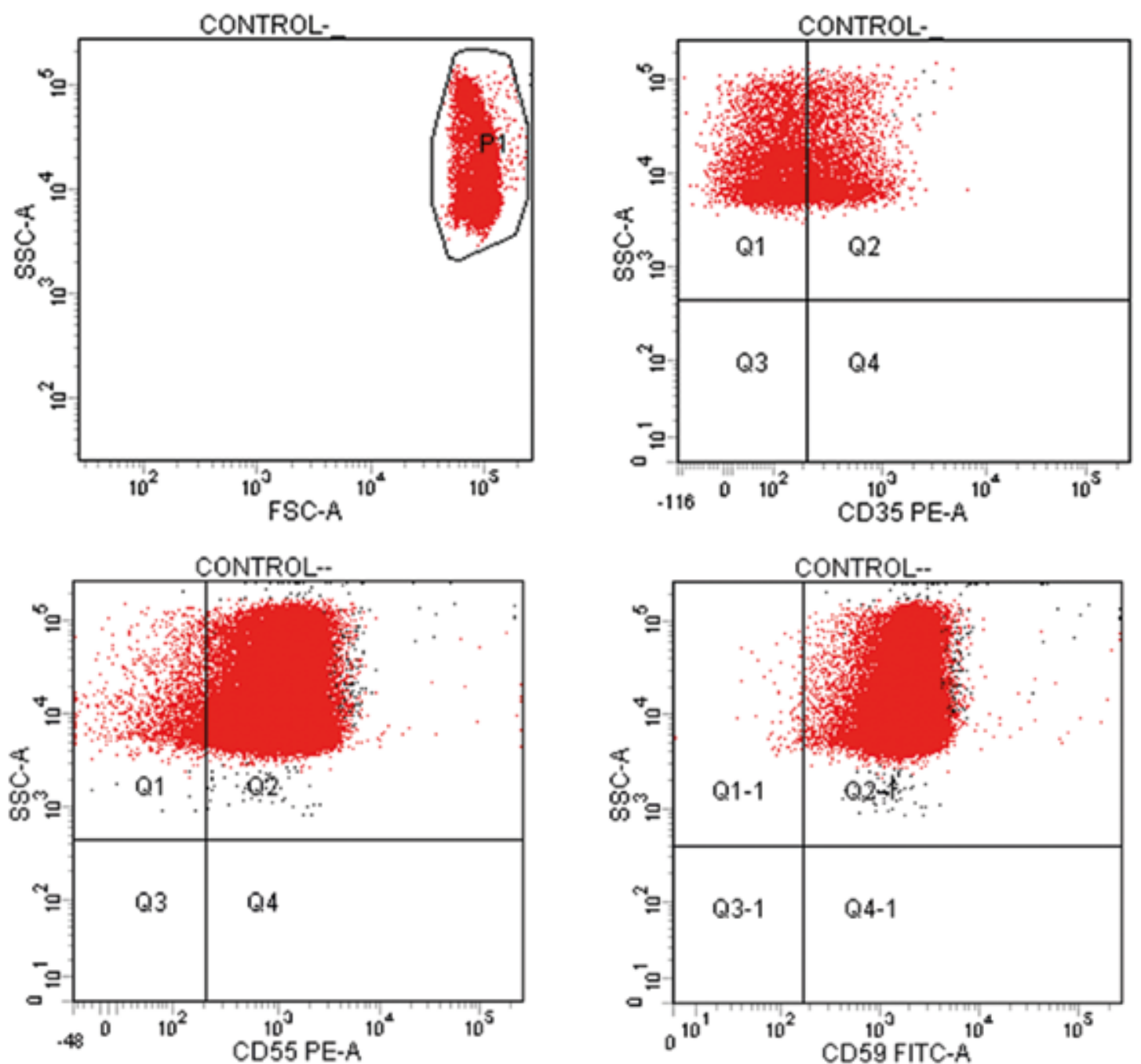

Fig. 1. Dot plot results of erythrocytes analyzed by flow cytometry. Red blood cells were gated on the basis of their forward and side scatter. Dot plot showed CD35 PE, CD59 FITC and CD55 PE expression on the gated RBCs of healthy controls

$11 \beta$-TI) [18]. We also found that while the level of expression of CD55 is significantly low in $\beta$-TM patients, that of CD59 is within normal range. Because CD35 expression was not studied in $\beta$-TM patients previously, we think that our study draws attention to the role of the complement system in the aetiopathogenesis of thalassaemia due to the low level of expression of CD35 detected in our study.

CD55 prevents C3 and C5 activation through all complement pathways by inhibiting formation and accelerating decay of C3/C5 convertases of both the classical and alternative pathways [19]. Alegretti et al. showed decreased CD55 and CD59 expression on RBCs of SLE patients with nephritis [13]. DAF deficiency led to a significantly increased incidence of proliferative glomerulonephritis [20]. The CD35/CR1 for C3b of erythrocytes has already been shown to bind complement-activating bacteria, viruses, and immune complexes, and deliver immune complexes to the fixed macrophages of liver and spleen [10]. CR1 is a receptor for both $\mathrm{C} 3 \mathrm{~b}$ and $\mathrm{C} 4 \mathrm{~b}$ and plays an important role in the removal of immune complexes coated with $\mathrm{C} 3 \mathrm{~b}$ and $\mathrm{C} 4 \mathrm{~b}$ [21]. Barros et al. showed that the expression of CD47 on RBCs of patients with warm autoimmune haemolytic anaemia is not different from that seen in healthy individuals. In addition, they detected that patients with active warm-type auto immune haemolytic anaemia present lower expression of CD59 and normal expression of CD35 and CD55 on their RBCs [17]. Somatic mutation in PIG-A gene causes a deficiency of glycosylphosphatidylinositol (GPI), a glycolipid that anchors these proteins onto the cell membrane. Lack of GPI causes loss of CD55 

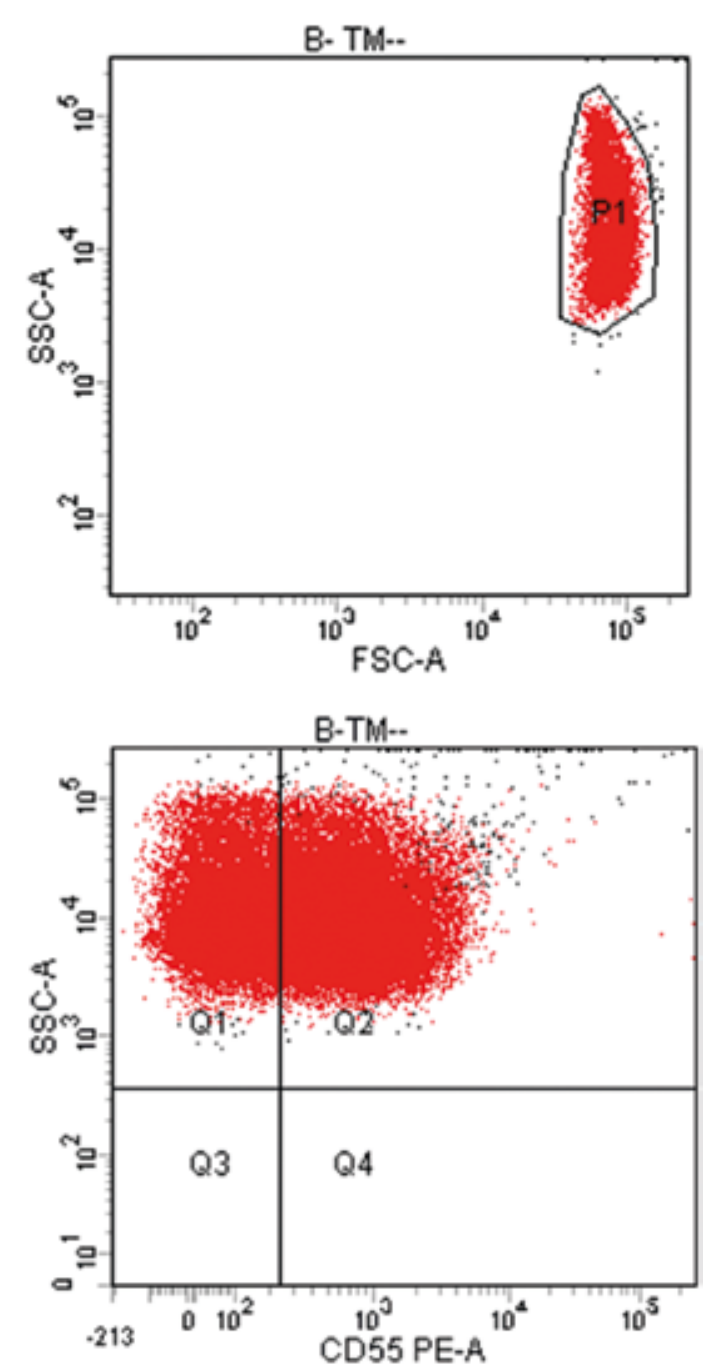
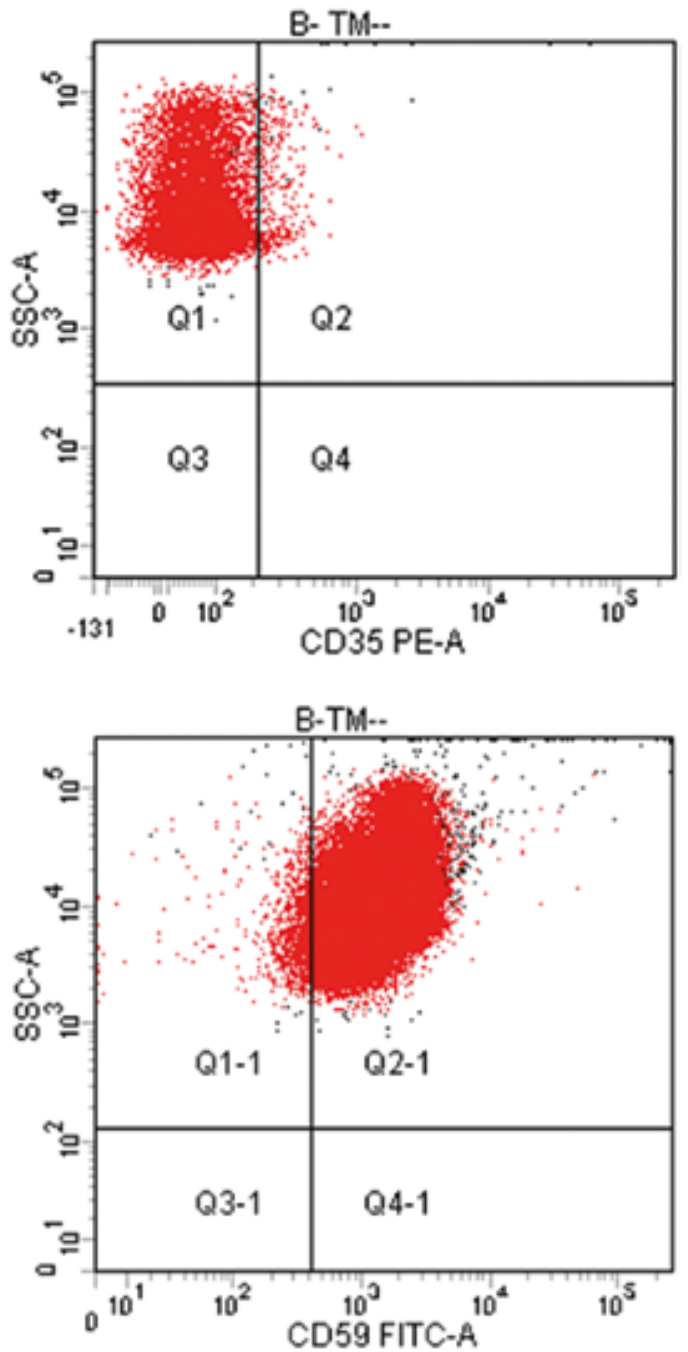

Fig. 2. Dot plot results of erythrocytes analyzed by flow cytometry. Red blood cells were gated on the basis of their forward and side scatter. Dot plot showed CD35 PE, CD59 FITC and CD55 PE expression on the gated RBCs of $\beta$-TM patients

and CD59, leading to excessive destruction of red cells in $\mathrm{PNH}$ [22].

In $\beta$-Thal, RBC destruction is related mainly to the changes occurring in the cell membrane, which can activate the complement deposition on RBCs [23, 24]. In addition, elicited auto-antibodies against the red cell membrane will sensitise RBCs and make them ready to be lysed via the reticuloendothelial system. Complement activation on the RBCs causes cell lysis, but these cells have regulator proteins that prevent lysis [25]. $\beta$-TM patients require frequent blood transfusions to live. Blood transfusion causes the transmission of autoantibodies of the donor to the recipient. Complement cascade is activated via autoantibodies in transfusion-dependent $\beta$-TM patients. Particularly functions of CD35 include control of complement activa- tion and the clearance of immune complexes [26]. In this study, we found that CD35 and CD55 levels were significantly lower in $\beta$-TM patients. Because CD35 and CD55 expressions are low on the surface of RBCs, activation of complement cascade is not regulated and haemolysis occurs. The reason for the low level of CD35 and CD55 may be a genetic defect related to synthesis of the synthesis of the proteins. There are more than 300 gene mutations defined in $\beta$-Thal patients in the literature [27]. Some of these mutations may alter the synthesis of CD35 and CD55 in the erythrocytes. The two red cell surface complement regulators, CD55 and CD59, are GPI (glycosylphosphatidylinositol)-linked proteins [28]. In our study the CD55 expression on the RBCs of $\beta$-TM patients was diminished to below that of the healthy controls, with a statistical sig- 

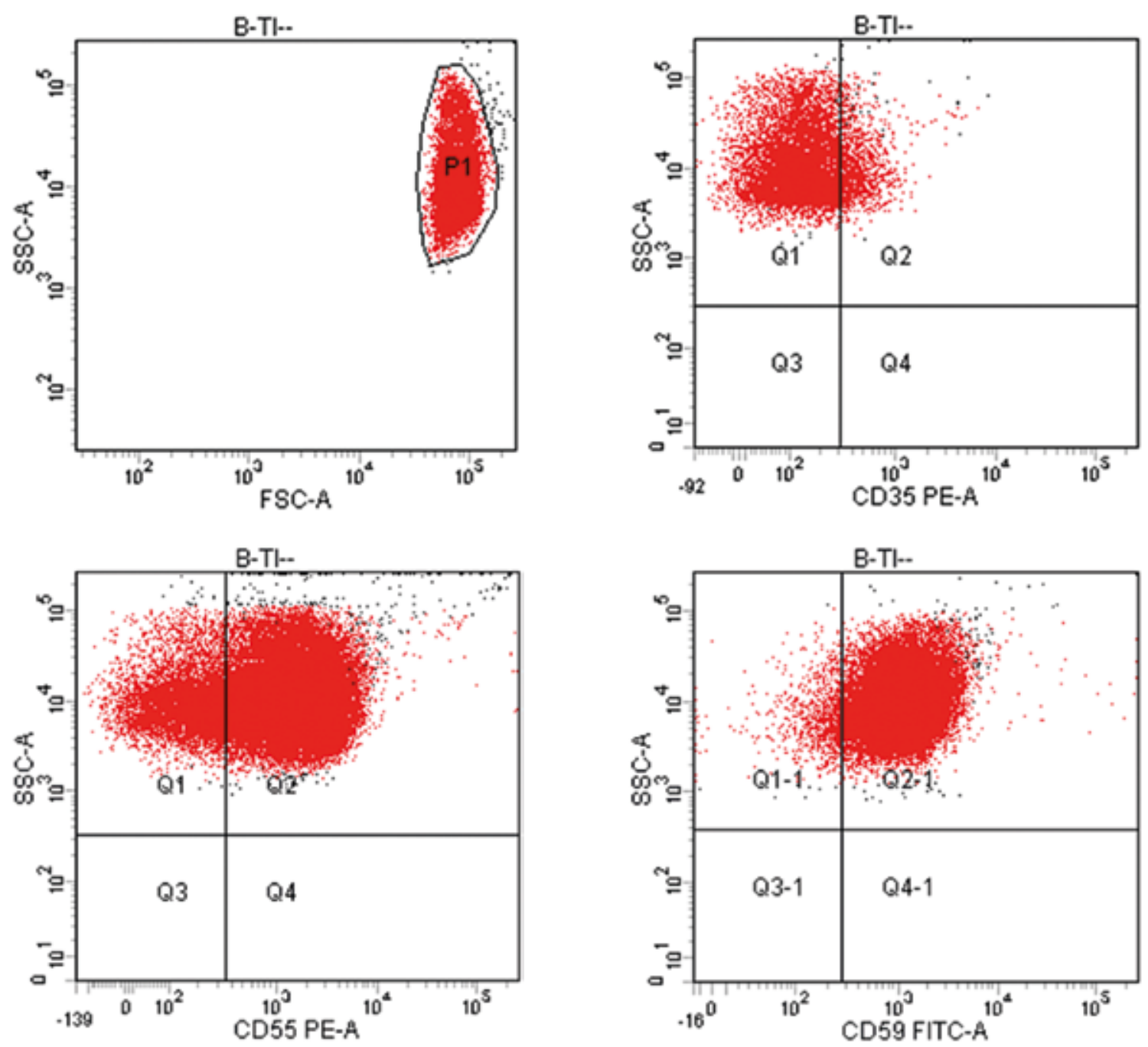

Fig. 3. Dot plot results of erythrocytes analyzed by flow cytometry. Red blood cells were gated on the basis of their forward and side scatter. Dot plot showed CD35 PE, CD59 FITC and CD55 PE expression on the gated RBCs of $\beta$-TI patients

nificance, while CD59 was not affected. This indicates that the affected cells have normal GPI-anchored type 1 surface proteins, and consequently they were not PNH clones. The mean number of CD35 molecules expressed on the RBC surface varies between individuals, typically between 50 and $1500 \mathrm{CD} 35$ molecules/RBC. Factors determining the variation in RBC CR1 expression are not fully understood, but are proposed to be both genetic and acquired [29]. Opi et al. found that CD35 levels are low on the surface of erythrocytes in patients with $\alpha$-thalassaemia. Also, it was stated that the low level of CD35 is related to the MCV value of these patients [30]. We conducted our study in $\beta$-Thal patients. The MCV value is lower in $\beta$-Thal patients compared to the healthy population. The MCV value was found to be significantly lower in both $\beta$-TM and
$\beta$-TI patients compared to the healthy population, consistent with the literature. Another reason for the low level of CD35 may be the low MCV value in our study. It remains unclear whether microcytic RBC synthesis is due to lower amounts of CR 1 in $\beta$-Thal than normal cells, or whether some CR1 is lost, for example, through exocytosis of membrane vesicles during normal RBC ageing, as well as by proteolysis, as described above. Increased vesiculation has been documented in $\alpha^{+}$thalassaemia RBCs, which might therefore provide a mechanism for CR1 loss. Also, changes caused by excess $\alpha$-globin tetramers on erythrocyte membrane may lead to low levels of CD35 and CD55 on the erythrocytes. We think that studies concerning the synthesis and destruction of CD35 and CD55 proteins will provide a positive effect on the prognosis of $\beta$-TM. 
In conclusion, $\beta$-TM patients suffer from increased haemolysis and a consequent increase in their demand for transfusion. Complement-mediated haemolysis was indicated in our study by underexpression of CD55 and CD35 in $\beta$-TM patients. This permits complement deposition on RBCs and enhances or accelerates their lysis. Low levels of CD55 and CD35 in $\beta$-TM patients indicate a role for them in the aetiopathogenesis of haemolysis in this disease, and also this defect in the complement system may be responsible for the chronic complications seen in these patients.

Detailed studies at the molecular level are needed to clarify the process under which the low expression is happening.

The present study was approved by the Ethics Committee of Antalya Education and Research Hospital (096/2015), Turkey.

The authors declare no conflict of interests.

\section{References}

1. Antonio C, Renzo G (2010): Beta-thalassemia. Genetics in Medicine 12: 61-76.

2. Rachmilewitz EA, Giardina PJ (2011). How I treat thalassemia Blood 118: 3479-3488

3. Galanello R, Origa R (2010) Beta-thalassemia. Orphanet J Rare Dis 5: 11; doi:10.1186/1750-1172-5-11

4. Ragab SM, Safan MA, Badr EA (2015): Study of serum haptoglobin level and its relation to erythropoietic activity in Beta thalassemia children. Mediterr J Hematol Infect Dis 7: e2015019.

5. Ruiz-Argüelles A, Llorente L (2007): The role of complement regulatory proteins (CD55 and CD59) in the pathogenesis of autoimmune hemocytopenias. Autoimmun Rev 6: 155-161.

6. DeZern AE, Uknis M, Yuan X Mukhina GL (2014): Complement blockade with a $\mathrm{C} 1$ esterase inhibitor in paroxysmal nocturnal hemoglobinuria. Exp Hematol 42: 857-861.

7. Mahajan RC, Narain K, MahantaJ (2011): Anaemia \& expression levels of CD35, CD55 \& CD59 on red blood cells in Plasmodium falciparum malaria patients from India. Indian J Med Res 133: 662-664.

8. Johnson JB, Borisevich V, Rocky B, Parks GD (2015): A novel factor activity in Nipah virus inhibits human complement pathways through cleavage of C3b. J Virol 89: 989-998.

9. Gwamaka M, Fried M, Domingo G, Duffy PE (2011): Early and extensive CD55 loss from red blood cells supports a causal role in malarial anaemia. Malar J 10: 386; doi: 10.1186/1475-2875-10-386.

10. Brodsky RA (2015): Complement in hemolytic anemia. Blood 126: 2459-2465.

11. Sayani FA, Kwiatkowski JL (2015): Increasing prevalence of thalassemia in America: Implications for primary care. Ann Med 47: 592-604.

12. Xu LH, Fang JP, Weng WJ (2012). Autoimmune hemolytic anemia in patients with $\beta$-thalassemia major. Pediatr Hematol Oncol. 29: 235-240.

13. Alegretti AP, Schneider L, Piccoli AK (2012): Diminished expression of complement regulatory proteins on peripheral blood cells from systemic lupus erythematosus patients. Clin Dev Immunol 2012: 725684; doi: 10.1155/2012/725684.
14. Veerreddy P (2013): Hemoglobinuria misidentified as hematuria: review of discolored urine and paroxysmal nocturnal hemoglobinuria. Clin Med Insights Blood Disord 20: 7-17.

15. Mahaian RC, Naran K, Mahanta J (2011): Anaemia \& expression levels of CD35, CD55 \& CD59 on red blood cells in Plasmodium falciparum malaria patients from india. Indian J Med Res 133: 662-664.

16. Varma S, Varma N, Reddy VV (2012): Detection of paroxysmal nocturnal hemoglobinuria-phenotype in patients with chronic lymphocytic leukemia and multiple myeloma. Indian J Pathol Microbiol 55: 206-210.

17. Barros MM, Yamamoto M, Figueiredo MS, Cançado R (2009): levels of CD47, CD35, CD55, and CD59 on red blood cells and signal-regulatory protein-alpha, beta on monocytes from patients with warm autoimmune hemolytic anemia. Transfusion 49: 154-160.

18. Obaid JM, Abo El-Nazar SY, Granem AM El-Hadidi AS (2014): Expression of CD55 on red blood cells of $\beta$-thalassemia patients. Hemoglobin. 38: 339-344.

19. Fang C, Miwa T, Shen H Song WC (2007): Complement-dependent enhancement of CD8+ T cell immunity to lymphocytic choriomeningitis virus infection in decay-accelerating factor-deficient mice. J Immunol 179: 3178-3186.

20. Bao L, Haas M, Minto AW Quigg RJ (2007): Decay-accelerating factor but not CD59 limits experimental immune-complex glomerulonephritis. Lab Invest 87: 357-364.

21. Rochowiak A, Niemir ZI (2010): The structure and role of CR1 complement receptor in physiology. Pol Merkur Leka 28: 79-83.

22. Dambal A, Nimbal NV, Kalsad ST, et al. (2015): Paroxysmal nocturnal haemoglobinuria masquerading as malaria: a case report. J Clin Diagn Res 9: OD03-4; doi: 10.7860/ JCDR/2015/13465.6329.

23. Obaid JM, Abo El-Nazar SY, Granem AM, El-Hadidi AS (2015): Compensation of CD55 underexpression on red blood cells of $\beta$-thalassemia major patients. Hemoglobin 39: 184189.

24. Meulenbroek EM, Wouters D, Zeerleder S (2014): Methods for quantitavive detection of antibody-induced complement activation on red blood cells. J Vis Exp 83: e51161.

25. Berentsen S, Sundic T (2015). Red blood cell destruction in autoimmune hemolytic anemia: role of complement and potential new targets for therapy. Biomed Res Int 2015: 363278; doi: $10.1155 / 2015 / 363278$.

26. Cockburn IA, Mackinnon MJ, O'Donnell A, et al. (2004): A human complement receptor 1 polymorphism that reduces Plasmodium falciparum rosetting confers protection against severe malaria. Proc Natl Acad Sci U S A 101: 272-277.

27. Kumar R, Singh K, Panigrahi I, Agarwal S (2013): Genetic heterogeneity of beta globin mutations among Asian-Indians and importance in genetic counselling and diagnosis. Mediterr J Hematol Infect Dis 5: e2013003; doi: 10.4084/ MJHID.2013.003.

28. Luzzatto L (2016): Recent advances in the pathogenesis and treatment of paroxysmal nocturnal hemoglobinuria. F1000Res. 23; 5. pii: F1000 Faculty Rev-209. doi: 10.12688/ f1000research.7288.1.

29. Khera R, Das N (2009): Complement receptor 1: disease associations and therapeutic implications. Mol Immunol 46: 761-772.

30. Opi DH, Uyoga S, Orori EN, et al. (2016): Red blood cell complement receptor one level varies with Knops blood group, $\alpha+$ thalassaemia and age among Kenyan children. Genes Immun 17: 171-178. 